\title{
Review
}

\section{H-SiC Schottky Barrier Diodes as Radiation Detectors: A Review}

\author{
Ivana Capan (D)
}

check for

updates

Citation: Capan, I. 4H-SiC Schottky Barrier Diodes as Radiation

Detectors: A Review. Electronics 2022, 11, 532. https://doi.org/10.3390/ electronics 11040532

Academic Editor: Jang-Yeon Kwon

Received: 19 January 2022

Accepted: 8 February 2022

Published: 10 February 2022

Publisher's Note: MDPI stays neutral with regard to jurisdictional claims in published maps and institutional affiliations.

Copyright: (C) 2022 by the author. Licensee MDPI, Basel, Switzerland. This article is an open access article distributed under the terms and conditions of the Creative Commons Attribution (CC BY) license (https:// creativecommons.org/licenses/by/ $4.0 /)$.
Ruđer Boškovic Institute, Bijenička 54, 10000 Zagreb, Croatia; capan@irb.hr

\begin{abstract}
In this review paper, an overview of the application of n-type 4H-SiC Schottky barrier diodes (SBDs) as radiation detectors is given. We have chosen $4 \mathrm{H}-\mathrm{SiC}$ SBDs among other semiconductor devices such as PiN diodes or metal-oxide-semiconductor (MOS) structures, as significant progress has been achieved in radiation detection applications of SBDs in the last decade. Here, we present the recent advances at all key stages in the application of $4 \mathrm{H}-\mathrm{SiC}$ SBDs as radiation detectors, namely: SBDs fabrication, electrical characterization of SBDs, and their radiation response. The main achievements are highlighted, and the main challenges are discussed.
\end{abstract}

Keywords: Schottky barrier diodes; $4 \mathrm{H}-\mathrm{SiC}$; radiation; detection

\section{Introduction}

Silicon carbide $(\mathrm{SiC})$ is a wide band gap semiconductor that is used in numerous semiconductor devices, such as PiN diodes, MOSFETs, and MEMS (Micro Electro-Mechanical Systems). This is due to the fact that $\mathrm{SiC}$ possesses a huge list of rather attractive properties, such as a wide band gap, large critical electric field, high thermal conductivity, high electron saturation velocity, chemical inertness, and radiation hardness [1].

Among all $\mathrm{SiC}$ polytypes, $4 \mathrm{H}$ has the largest band gap of $3.26 \mathrm{eV}$, and it is the most studied. For comparison, some of the physical parameters for $\mathrm{SiC}$ polytypes are given in Table 1. Due to the high and isotropic mobility of charge carriers, the $4 \mathrm{H}$ polytype of $\mathrm{SiC}$ is preferred as a material for power electronics [1], bipolar devices [2], and quantum sensing [3]. Moreover, $4 \mathrm{H}-\mathrm{SiC}$ has attracted considerable interest in recent years as a very promising material for radiation detection in harsh environments where detectors are exposed to high temperatures and high fluencies of radiation $[1,4,5]$.

Table 1. Physical properties of SiC polytypes [1].

\begin{tabular}{ccccc}
\hline $\begin{array}{c}\text { Polytype } \\
\text { SiC }\end{array}$ & $\begin{array}{c}\text { Energy Band } \\
\text { Gap (eV) }\end{array}$ & $\begin{array}{c}\text { Electron Mobility } I I / \perp \\
\text { to } c \text {-axis } \\
\left(\mathbf{c m}^{\mathbf{2}} \cdot \mathbf{V}^{-\mathbf{1}} \cdot \mathbf{s}^{-\mathbf{1}}\right)\end{array}$ & $\begin{array}{c}\text { Hole Mobility } \\
\left(\mathbf{c m}^{\mathbf{2}} \cdot \mathbf{V}^{-\mathbf{1}} \cdot \mathbf{s}^{-\mathbf{1}} \mathbf{)}\right.\end{array}$ & $\begin{array}{c}\text { Electric Field II to } \\
\boldsymbol{c} \text {-axis } \\
(\mathbf{M V} / \mathbf{c m})\end{array}$ \\
\hline $4 \mathrm{H}$ & 3.26 & $1200 / 1020$ & 120 & 2.8 \\
$6 \mathrm{H}$ & 3.02 & $100 / 450$ & 100 & 3.0 \\
$3 \mathrm{C}$ & 2.36 & $\sim 1000 / 1000$ & 100 & 1.4 \\
\hline
\end{tabular}

The widespread applicability of $4 \mathrm{H}-\mathrm{SiC}$ material for radiation detection was mostly hindered by the trapping/recombination of charge carriers and compensation effects due to electrically active deep-level defects.

Recent progress in the manufacturing of high-quality epitaxial $4 \mathrm{H}-\mathrm{SiC}$ has enabled unprecedented detection properties of the $4 \mathrm{H}-\mathrm{SiC}$ detectors for alpha-particles and neutrons, as reported in numerous studies [5-10]. Moreover, promising results for low-energy gamma and X-ray detection have also been reported [11,12].

A wide interest in using $4 \mathrm{H}-\mathrm{SiC}$ for radiation detection applications has been driving the development of semiconductor devices, such as 4H-SiC PiN diodes [13] or MetalOxide-Semiconductor (MOS) devices [14]. However, such devices will not be included 
in this review, as we will strictly focus on SBDs as one of the simplest and most widely used radiation detectors. Moreover, we should keep in mind that other wide band gap materials such as $\mathrm{GaN}$ [15], diamond [16], and $\mathrm{Ga}_{2} \mathrm{O}_{3}$ [17] are also being considered as useful materials for radiation-detection applications. The comparison between different materials requires a separate research paper, and therefore it will not be addressed within this review paper.

The main aim of this review is to help graduate students and researchers who are at the initial stage of their research on radiation detection applications of $4 \mathrm{H}-\mathrm{SiC}$ SBDs. This review will give them a practical overview of the main stages in the process of the application, starting from the SBDs fabrication up to measuring and analyzing detector response to various radiation sources (alpha particles, neutrons, gamma, and X-rays). It should be noted that each stage in the process deserves a dedicated research paper that would allow for all issues to be comprehensively addressed. Here, we have tried to pinpoint the key issues for each stage. Therefore, we highly recommend to our readers to look for more details in provided references and references therein.

\section{4H-SiC Schottky Barrier Diodes}

SBDs (metal-semiconductor junctions) are among the most fundamental structures, and yet the most interesting, for the realization of radiation detectors. A typical $4 \mathrm{H}-\mathrm{SiC}$ SBD used for radiation detection is shown in Figure 1. Due to band alignment, a volume depleted of charge carriers is created at the semiconductor side of the junction, making the device very sensitive to the presence of electron-hole pairs generated upon exposure to ionizing radiation. The SBD is operated under reverse bias, which increases the potential drop across the semiconductor and increases the depletion region width. The depletion region width is controlled by the applied bias and the doping level. For radiation applications, low-doped materials are used. Typical doping levels for the epitaxial layer are between $10^{12}$ and $10^{14} \mathrm{~cm}^{-3}$.

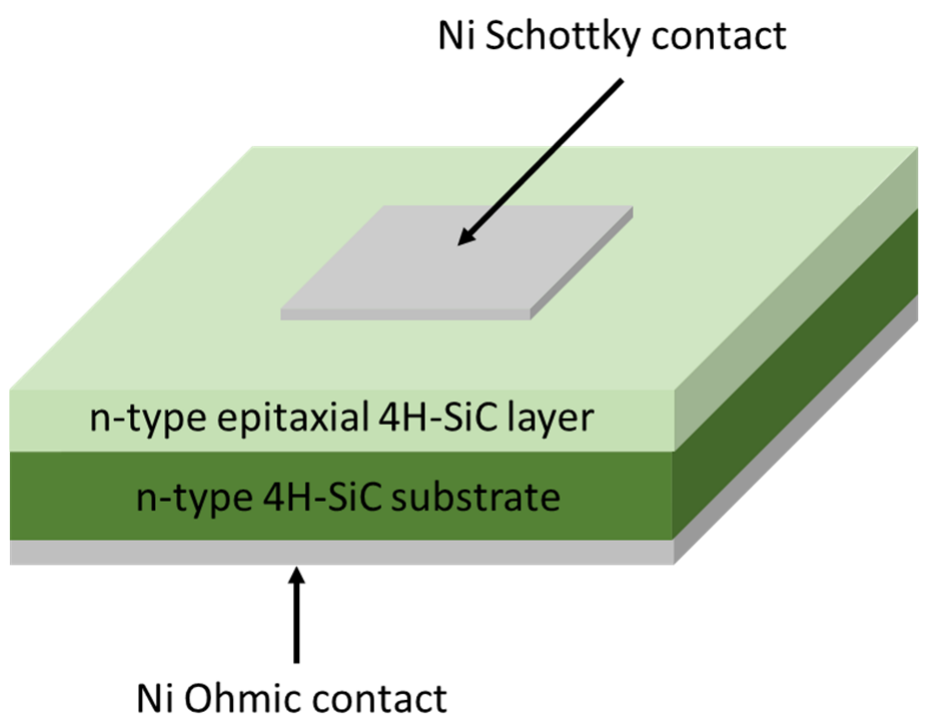

Figure 1. A scheme of the $4 \mathrm{H}-\mathrm{SiC}$ SBD used for radiation detection.

\subsection{Important Parameters of $4 \mathrm{H}-\mathrm{SiC}$ SBDs}

Two important parameters for SBDs that are important for radiation detection applications to be addressed in this overview are (1) epitaxial layer thickness and the (2) Schottky contact area.

The epitaxial layer thickness is linked to the depletion region width. To have an efficient radiation detector, a fully depleted region is desired. The first step is to use the low-doped material, and the next step is the applied voltage. The high operating voltages are needed to achieve a full depletion for the thick epitaxial layers and vice versa. 
As mentioned in the previous section, significant progress in the manufacturing of high-quality epitaxial $4 \mathrm{H}-\mathrm{SiC}$ layers has enabled its widespread application in radiation detection. Typically reported thicknesses of epitaxial $4 \mathrm{H}-\mathrm{SiC}$ in SBDs used for radiation detection are in the range starting from a few $\mu \mathrm{m}$ up to $100 \mu \mathrm{m}$ [5-11]. Radulović et al. [4] have reported neutron radiation tests using the SBDs with $170 \mu \mathrm{m}$, while Kleppinger et al. [8] have recently reported the thickest $4 \mathrm{H}-\mathrm{SiC}$ epitaxial layer $(250 \mu \mathrm{m})$ used for radiation-detection applications. Thicknesses up to $250 \mu \mathrm{m}$ have the best-reported quality, and they are almost free from electrically active defects. The most dominant defects present in the as-grown $4 \mathrm{H}-\mathrm{SiC}$ material are acceptor $(=/ 0)$ and donor $(++/ 0)$ states of the carbon vacancy $\left(\mathrm{V}_{\mathrm{c}}\right)$, known as $\mathrm{Z}_{1 / 2}$ and $\mathrm{EH}_{6 / 7}$, respectively $[8,18,19]$. Electrically active defects will be explained later in the text.

Another parameter important for radiation detection applications is the area of the Schottky contact. By increasing the area, we are opening a "window" for the incoming particles to be detected. However, as we shall explain later in the text, the area of the Schottky contact affects the transport properties of the SBD, and certain limitations are needed as Schottky contact is usually fabricated by thermal evaporation of nickel (average thickness around $100 \mu \mathrm{m}$ ) through a mask with openings in different sizes. The most common reported values for Schottky contact areas vary from $1 \mathrm{~mm}^{2}$ up to $20 \mathrm{~mm}^{2}$ [4-11].

\subsection{Electrical Parameters of $4 \mathrm{H}-\mathrm{SiC}$ SBDs and the Impact of Radiation}

Upon SBD fabrication, the first step is to check electrical properties, and that includes temperature-dependent current-voltage (I-V-T) and capacitance-voltage (C-V-T) measurements.

From these measurements, we obtain crucial information on device properties and estimate parameters such as ideality factor, Schottky barrier height, series resistance, Richardson constant, free carrier concentration, and doping depth profile. The forward-biased I-V-T measurements usually give information on transport properties, ideality factors, and Schottky barrier height $[7,8]$.

$\mathrm{I}-\mathrm{V}$ and $\mathrm{C}-\mathrm{V}$ measurements are usually performed before and after radiation tests. To obtain information about the quality of the fabricated SBDs, for example, to check the leakage current and estimate the physical parameters, measurements are performed before the radiation tests. As radiation can introduce damage into the material and affect the electrical properties of SBDs, for example, increase the leakage current and lead to the charge carrier removal, measurements are also performed after radiation tests.

Figure 2 shows reverse-biased I-V measurements at room temperature (RT) for the $4 \mathrm{H}-\mathrm{SiC}$ SBD before and after exposure to thermal neutron radiation [20]. As SBDs are operating under reverse voltage for radiation-detection applications, such measurements are needed. SBD parameters are the following: $4 \mathrm{H}-\mathrm{SiC}$ epilayer thickness of $25 \mu \mathrm{m}$, and SBD area of $9 \mathrm{~mm}^{2}$. The thermal neutron radiation measurements were performed at the JSI TRIGA reactor. The neutron flux was $8.8 \times 10^{6} \mathrm{n} \mathrm{cm}^{-2} \mathrm{~s}^{-1}$ [20]. As seen in Figure 2 the leakage current is very low $\left(\sim 10^{10} \mathrm{~A}\right)$, and it was not affected by thermal neutron radiation. An increase in the series resistance of SBD is observed from forward I-V characteristics at neutron fluences higher than $10^{13} \mathrm{~cm}^{-2}$ [21].

Figure 3 shows high-frequency $(1 \mathrm{MHz}) \mathrm{C}-\mathrm{V}$ measurement at $\mathrm{RT}$ for $4 \mathrm{H}-\mathrm{SiC} \mathrm{SBD}$ before and after it was exposed to alpha particles radiation [9]. The SBD parameters are a $4 \mathrm{H}-\mathrm{SiC}$ epilayer thickness of $25 \mu \mathrm{m}$ and an SBD area of $1 \mathrm{~mm}^{2}$. The SBDs were irradiated with alpha particles using the ${ }^{241} \mathrm{Am}$ source under the low vacuum at $1 \mathrm{mbar}$ and a sourceSBD distance of $2 \mathrm{~mm}$ [9]. The $\mathrm{C}-\mathrm{V}$ characteristic is unchanged upon radiation tests with alpha particles.

Since alpha particles did not introduce any damage, neutron irradiations were also performed to study their impact on the $\mathrm{C}-\mathrm{V}$ characteristics of $\mathrm{SiC}$ SBDs. Figure 4 shows the doping concentration profiles of the as-prepared and neutron-irradiated 4H-SiC SBDs (solid lines, left $y$ axis) and the calculated vacancy concentration profile (dashed line, right $y$ axis). SBD parameters are a $4 \mathrm{H}-\mathrm{SiC}$ epilayer thickness of $25 \mu \mathrm{m}$ and an SBD area of $1 \mathrm{~mm}^{2}$. 
The SBDs were irradiated with epithermal and fast neutrons with the neutron fluence up to $10^{13} \mathrm{~cm}^{-2}$ [22].

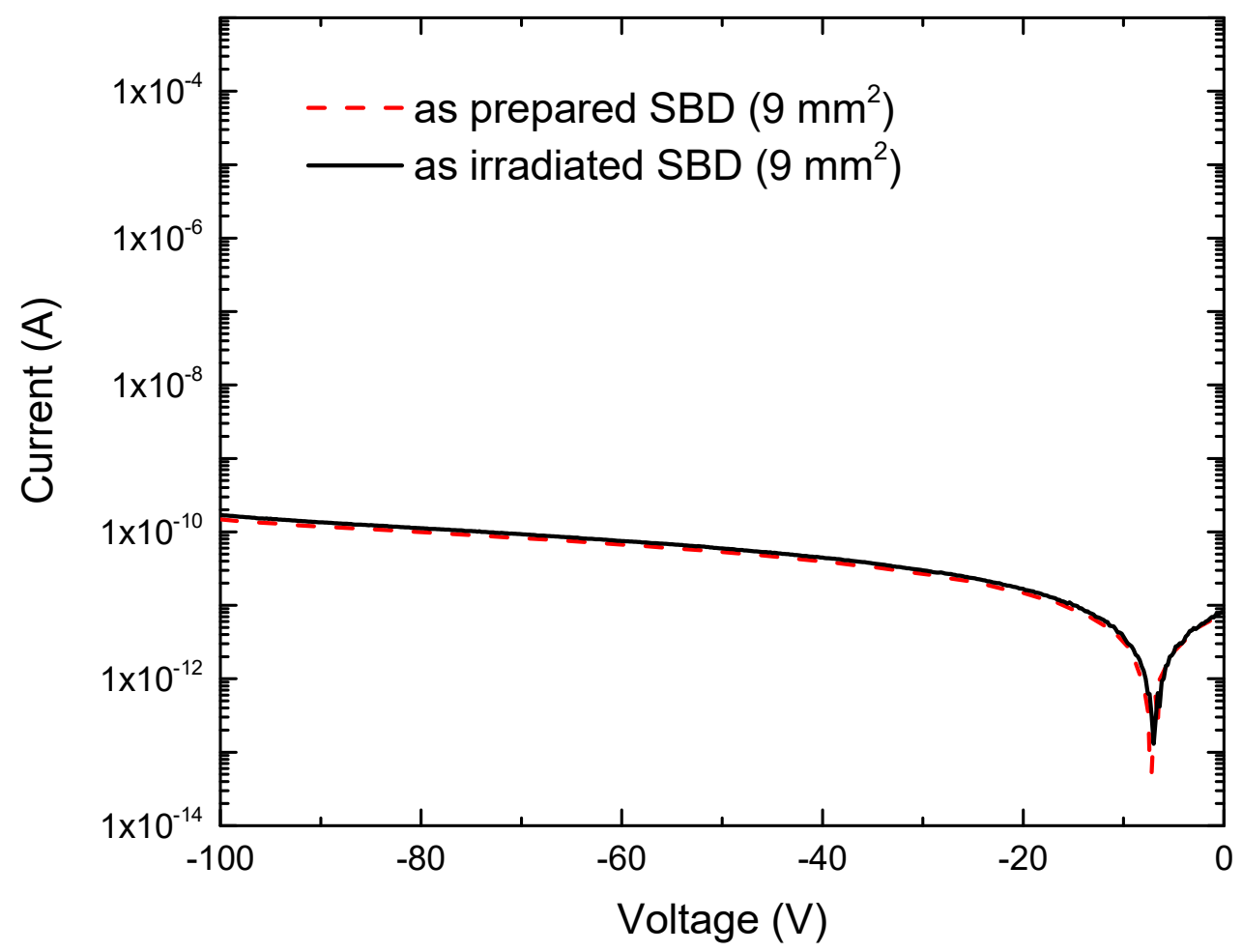

Figure 2. I-V measurement at $\mathrm{RT}$ of $4 \mathrm{H}-\mathrm{SiC} \mathrm{SBD}$ before and after the neutron radiation tests. Data adapted from Ref. [20].

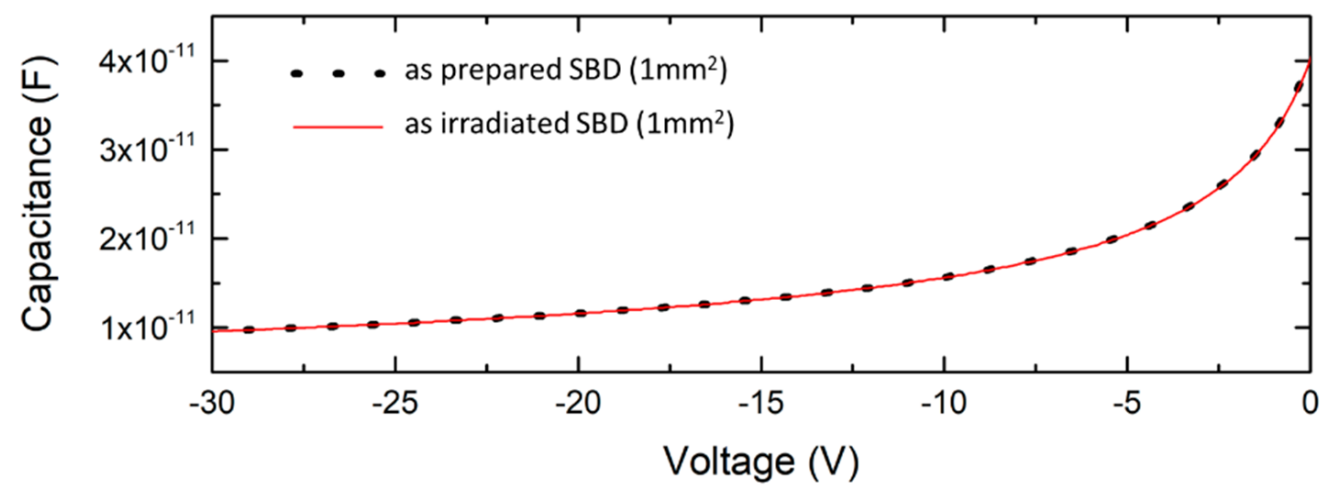

Figure 3. $\mathrm{C}-\mathrm{V}$ measurements at $\mathrm{RT}$ of $4 \mathrm{H}-\mathrm{SiC} \mathrm{SBD}$ before and after the alpha particle radiation tests. Data adapted from Ref. [9].

A slight decrease in the free carrier concentration is detected upon neutron radiation tests. This is due to the electrically active defects introduced by neutron radiation. The displacement damage introduced by neutron irradiation in the 4H-SiC SBD was simulated by FLUKA software [23]. Such simulations are an integral part of the electrical characterization of an SBD, before and after SBD was exposed to radiation, as they provide useful information on the concentration of introduced defects and their depth distribution. 


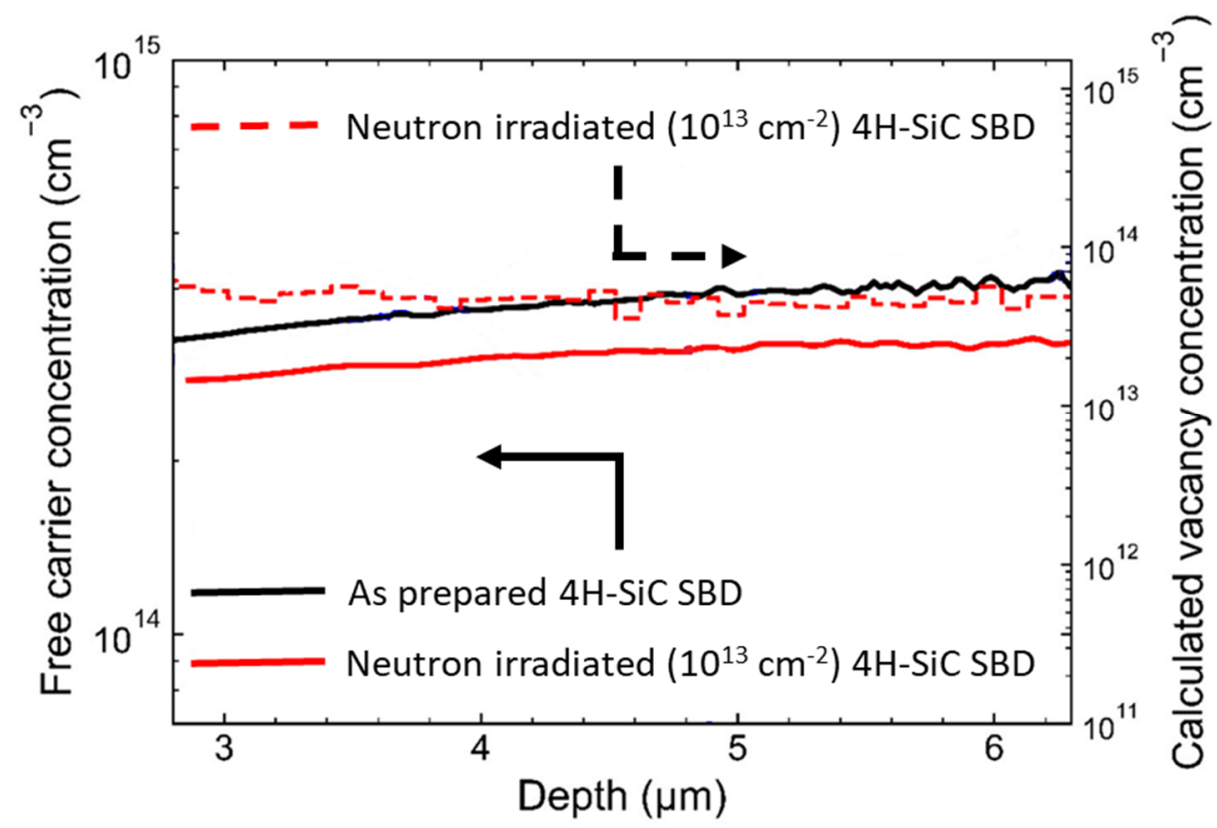

Figure 4. Free-carrier concentration profiles of as prepared and neutron-irradiated n-type $4 \mathrm{H}-\mathrm{SiC}$ SBD (solid lines, left $y$-axis). The calculated vacancy concentration profile for neutrons using FLUKA software (red, dashed, right $y$-axis). The free carrier concentration profiles are obtained from the $\mathrm{C}-\mathrm{V}$ measurements. Adapted from Ref. [22].

\subsection{Electrically Active Deep Level Defects in $4 \mathrm{H}-\mathrm{SiC}$ SBDs}

Another step in the electrical characterization of SBDs is to look for electrically active deep-level defects in as-prepared and/or as-irradiated SBDs. Electrically active deep-level defects act as traps for charge carriers and therefore influence the electrical properties of SBDs and cause a deterioration of detector performance. These defects are mainly created during (i) semiconductor material growth, (ii) processing by ion implantation, or (iii) operation in a harsh ionizing radiation environment.

To obtain information about defects, deep-level transient spectroscopy (DLTS) is mostly used. DLTS is a well-established technique, and it is the most sensitive method for measurements of electronic properties of deep-level defects in semiconductors; it can detect deep-level defects in concentrations around $10^{9} \mathrm{~cm}^{3}$ [24]. It provides information regarding the activation energy for electron/hole emission and capture cross-section and concentration/density of defects. These data are crucial for defining a "defect fingerprint".

Electrically active defects in $4 \mathrm{H}-\mathrm{SiC}$ material are ordinarily introduced during crystal growth. Figure 5 shows the DLTS spectrum for the as-prepared $4 \mathrm{H}-\mathrm{SiC}$ SBD. One peak with a maximum of around $320 \mathrm{~K}$ is present. This peak labeled as $Z_{1 / 2}$ was previously assigned to the $(=/ 0)$ transition from the carbon vacancy $\left(\mathrm{V}_{\mathrm{C}}\right)$ and was extensively studied in past decades $[18,19,25,26]$. It is usually present in the as-prepared material in concentrations in the range of $10^{11}-10^{13} \mathrm{~cm}^{-3}$. In addition to $Z_{1 / 2}, V_{c}$ introduces another deep level in n-type $4 \mathrm{H}-\mathrm{SiC}$. That level, labeled asEH $6 / 7$, introduces a broad peak in the DLTS spectrum at around $650 \mathrm{~K}$ (not shown here), and it is ascribed to (++/0) transitions from $\mathrm{V}_{\mathrm{c}}[8,19]$.

In addition to as-grown defects in $4 \mathrm{H}-\mathrm{SiC}$ SBDs, there is a whole group of electrically active defects in $4 \mathrm{H}-\mathrm{SiC}$ introduced by protons, neutrons, electrons, ions, etc.

The most dominant defects are silicon vacancy $\left(\mathrm{V}_{\mathrm{Si}}\right)$ [3], carbon interstitials $\left(\mathrm{C}_{\mathrm{i}}\right)$ [27], and carbon antisite-carbon vacancy (CAV) complex [28]. More details on radiation-induced defects can be found in the above-mentioned references and references within. Figure 6 shows the DLTS spectrum for the n-type $4 \mathrm{H}-\mathrm{SiC}$ SBD irradiated with epithermal and fast neutrons. Neutron irradiation has introduced two electrically active defects, labeled as S1 and S2, and they are assigned to Vsi $[3,29]$. Neutron irradiations with fluencies $10^{14} \mathrm{~cm}^{-2}$ and higher caused irreversible damage in SBDs [21]. 


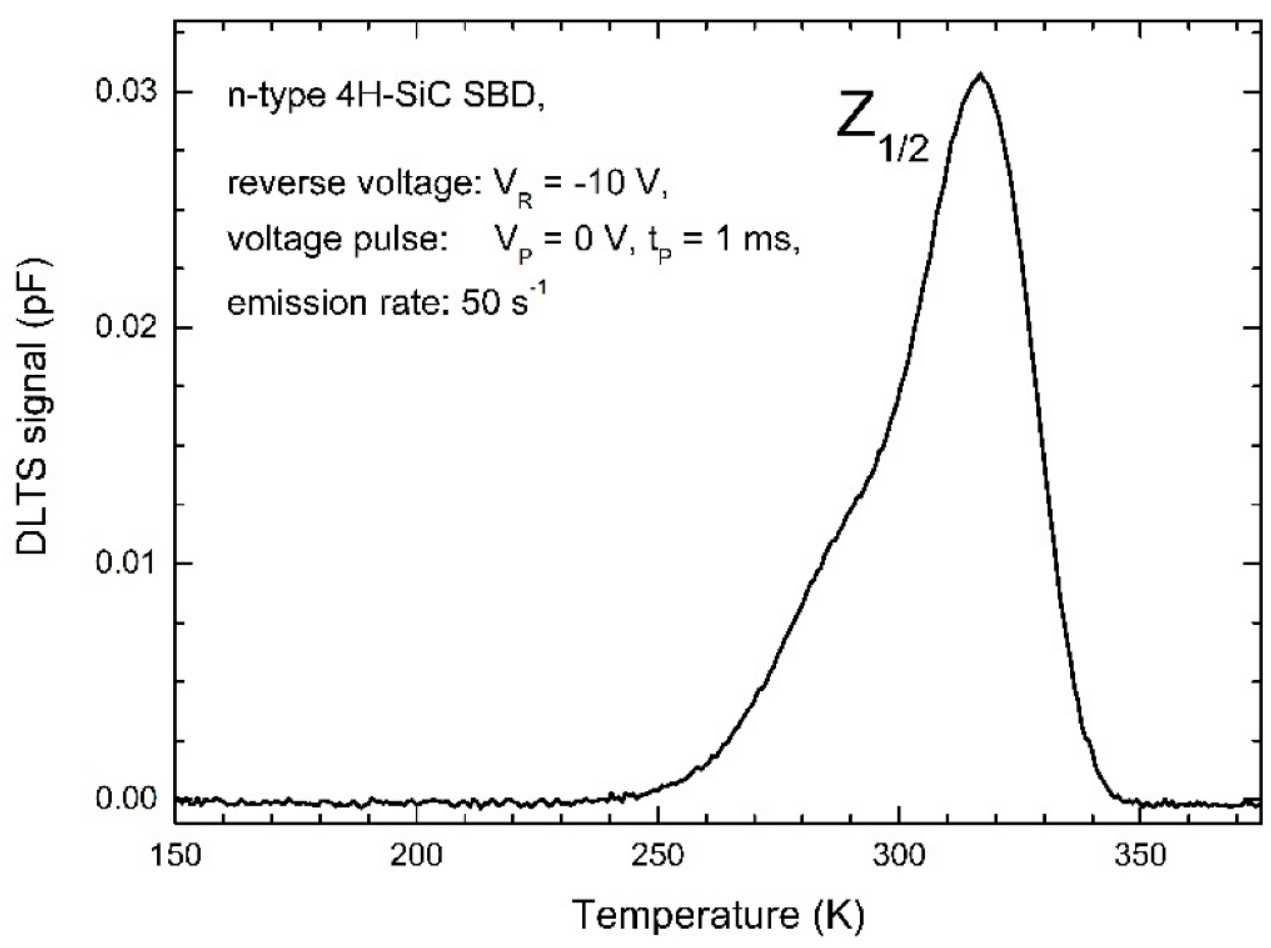

Figure 5. Typical DLTS spectrum for as prepared n-type 4H-SiC SBD. Data reproduced from Ref. [9].

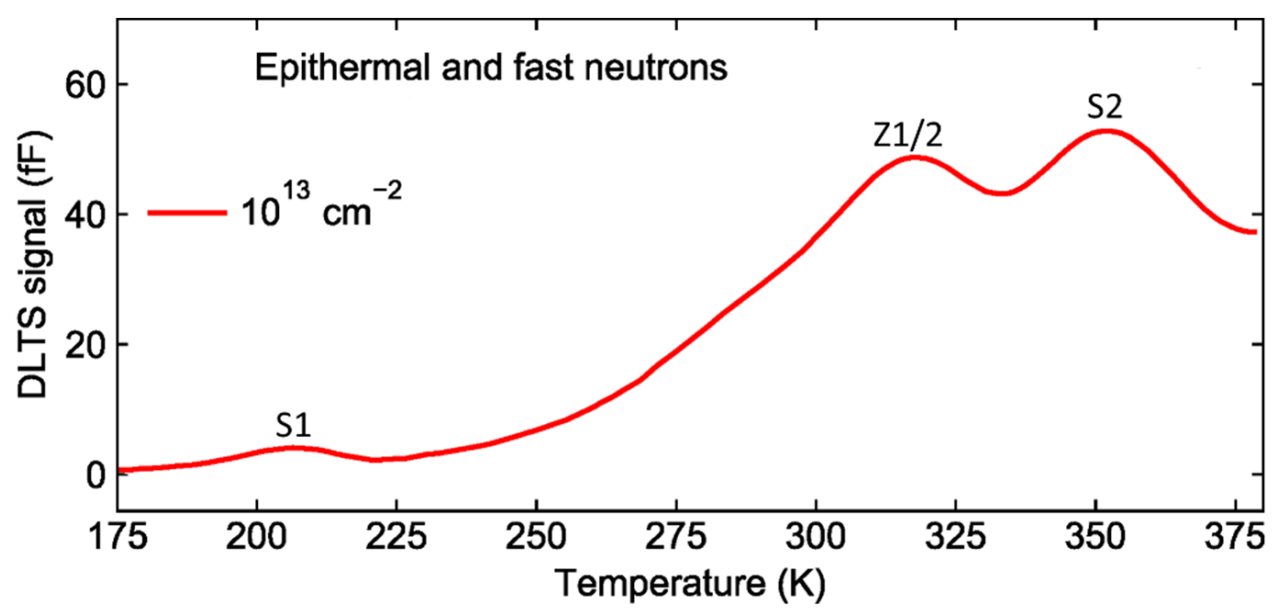

Figure 6. DLTS spectrum for the n-type 4H-SiC SBD irradiated with epithermal and fast neutrons. The neutron fluence was $10^{13} \mathrm{~cm}^{-2}$. The data are adapted from Ref. [29].

\section{Radiation Response of $4 \mathrm{H}-\mathrm{SiC}$ SBDs}

To efficiently test and analyze the radiation response of fabricated $4 \mathrm{H}-\mathrm{SiC}$ SBDs, an electronic read-out system is needed. Although the systems can vary from each study, depending on the applications, the key elements are basically identical for all systems. Here, we briefly describe the electronic system consisting of a charge-sensitive preamplifier, a shaping amplifier, a high voltage module, a power supply, and a multichannel analyzer. A standalone battery-powered power supply is useful in minimizing electronic noise. The block diagram of the electronic system is shown in Figure 7. 


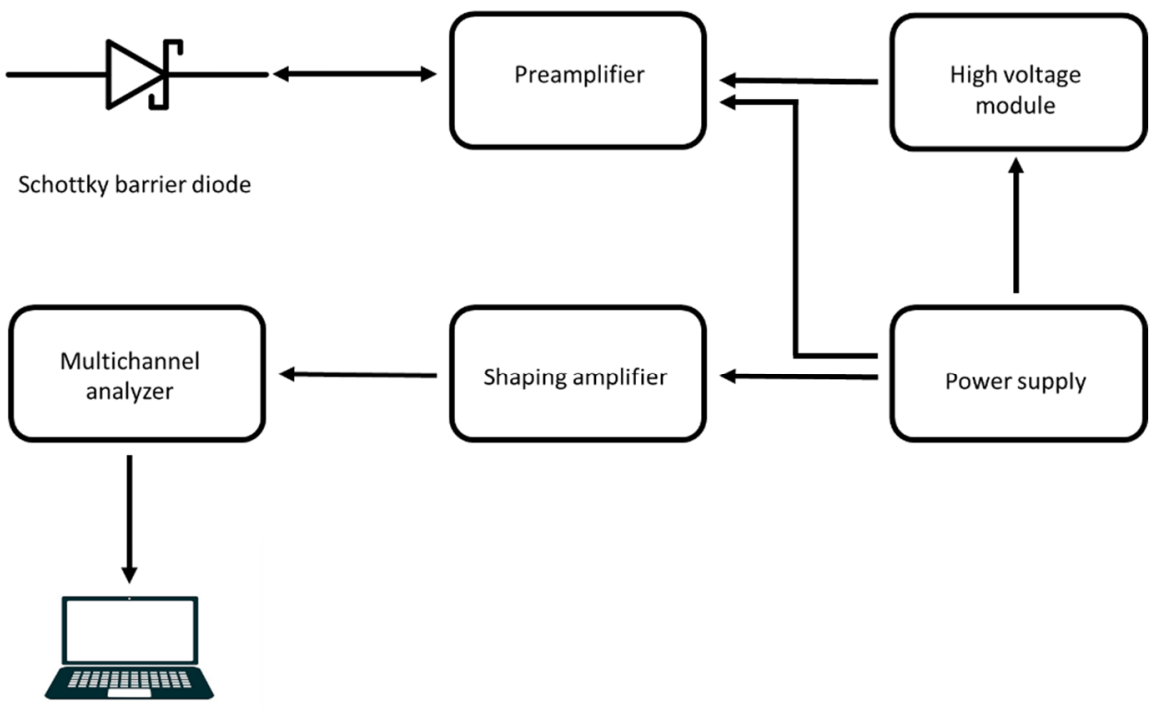

Figure 7. Block diagram of the basic detector system.

\subsection{Response to Alpha Radiation}

The vast majority of reported studies on radiation response of $4 \mathrm{H}-\mathrm{SiC}$ SBD include radiation tests with alpha particles. The pioneering work in this area was made by Ruddy et al. [6]. A linear energy response and excellent energy resolution were obtained for various alpha emitters in the 3.18-8.38 MeV energy range. Recent advances in energy resolution and efficiency have been reported by several groups [7-9,30-33]. Zat'ko et al. [7] used $4 \mathrm{H}-\mathrm{SiC}$ SBDs with various epitaxial layer thicknesses ranging from 25 up to $70 \mu \mathrm{m}$ and Schottky contacts with 2.0 or $3.0 \mathrm{~mm}$ in diameter. They reported a high-energy resolution below $20 \mathrm{keV}$ in the full width at half-maximum (FWHM) for $5.5 \mathrm{MeV}$ alpha particles. Kleppinger et al. [8] made additional progress by applying the thickest $4 \mathrm{H}-\mathrm{SiC}$ epilayer of $250 \mu \mathrm{m}$. The Schottky contacts were $2.9 \mathrm{~mm}$ or $3.9 \mathrm{~mm}$ in diameter. They reported a similar energy resolution of less than $0.5 \%$ FWHM for $5.5 \mathrm{MeV}$ alpha particles. Chaudhuri et al. [33] used a $20 \mu \mathrm{m}$-thick $4 \mathrm{H}-\mathrm{SiC}$ epitaxial layer and achieved an energy resolution of $0.29 \%$ FWHM for $5.48 \mathrm{MeV}$ alpha particles. Bernat et al. [9] reported the charge collection efficiency (CCE) of fully depleted $4 \mathrm{H}-\mathrm{SiC}$ SBDs to detect alpha particles from a large-area ${ }^{241} \mathrm{Am}$ source up to $100 \%$. They have achieved an energy resolution of $3 \%$ FWHM for $5486 \mathrm{keV}$.

Figure 8 shows a typical spectral response of an SBD to the mixed energy alpha particles [9]. SBD parameters are the following: a 4H-SiC epilayer thickness of $25 \mu \mathrm{m}$ and Schottky contact area of $4 \mathrm{~mm}^{2}$.

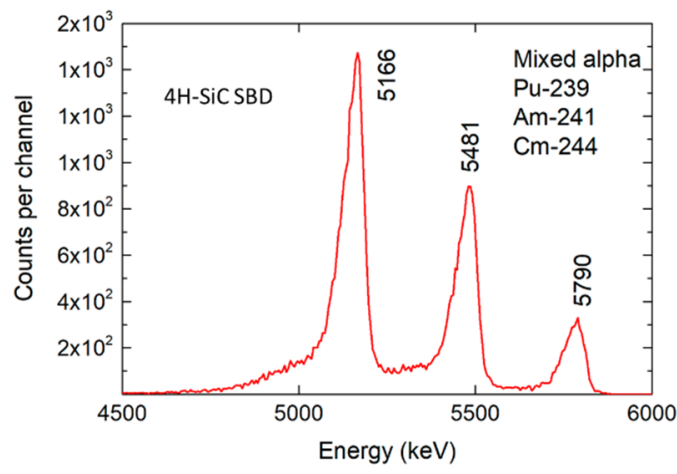

(a)

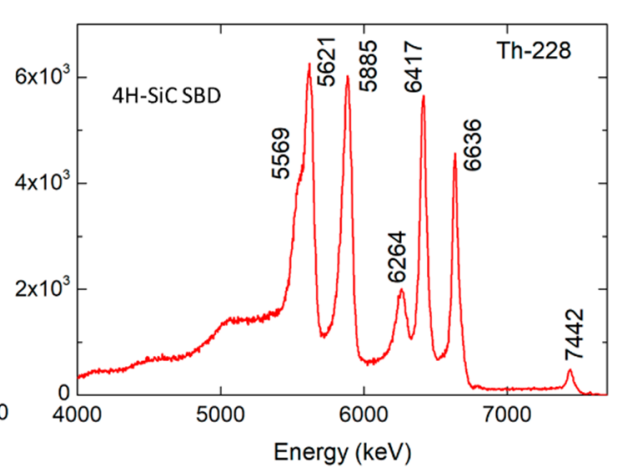

(b)

Figure 8. (a) Response of the $4 \mathrm{H}-\mathrm{SiC}$ SBD to mixed alpha particle source (Pu-239, Am-241, Cm-244) and (b) response of the same 4H-SiC SBD to Th-228 alpha reference source. Data reproduced from Ref. [9]. 
Based on the available literature data, we may conclude that the $4 \mathrm{H}-\mathrm{SiC}$ SBDs are an efficient radiation detector for alpha particles, with energy resolutions being continuously improved.

\subsection{Response to Neutron Radiation}

Since SiC material is suitable for radiation-hard environments, the $4 \mathrm{H}-\mathrm{SiC}$ SBDs have attracted a lot of interest for applications in nuclear science and nuclear safety [4,5]. In the case of neutron detection, $4 \mathrm{H}-\mathrm{SiC}$ SBDs could be used to detect thermal and fast neutrons. As thermal neutrons could not be directly detected by $4 \mathrm{H}-\mathrm{SiC}$, their presence is observed from detecting ionizing neutron reaction products, such as alpha particles, tritons, and others. Therefore, an efficient thermal neutron detection is achieved by using a converter layer rich in isotopes with a large cross-section for neutrons with energy in the range of $\mathrm{k}_{\mathrm{B}} \mathrm{T}$ at room temperature (with $\mathrm{k}_{\mathrm{B}}$ representing the Boltzmann constant). The most used are ${ }^{6} \mathrm{Li}$ and ${ }^{10} \mathrm{~B}$ converter layers [34].

Results on the radiation response of $4 \mathrm{H}-\mathrm{SiC}$ SBDs to thermal neutrons have been reported in numerous studies. The highest reported efficiency is about 5\% [35-37]. Bernat et al. [20] achieved a thermal neutron efficiency of $4.67 \%$ with ${ }^{6} \mathrm{LiF}$ converter layers. Lower efficiency $\left(2.24 \%\right.$ ) was achieved with ${ }^{10} \mathrm{~B}_{4} \mathrm{C}$ converter layers.

Figure 9 shows the radiation response of $4 \mathrm{H}-\mathrm{SiC}$ SBD equipped with a ${ }^{6} \mathrm{LiF}$ converter to the thermal neutron field. SBD parameters are a $4 \mathrm{H}-\mathrm{SiC}$ epitaxial layer thickness of 25 $\mu \mathrm{m}$ and Schottky contact area of $4 \mathrm{~mm}^{2}$. Two maxima are expected, one for alpha particles at $2050 \mathrm{keV}$ and the other for tritons at $2730 \mathrm{keV}$ (dashed lines, Figure 9). Those maxima are clearly visible in the measured radiation response.

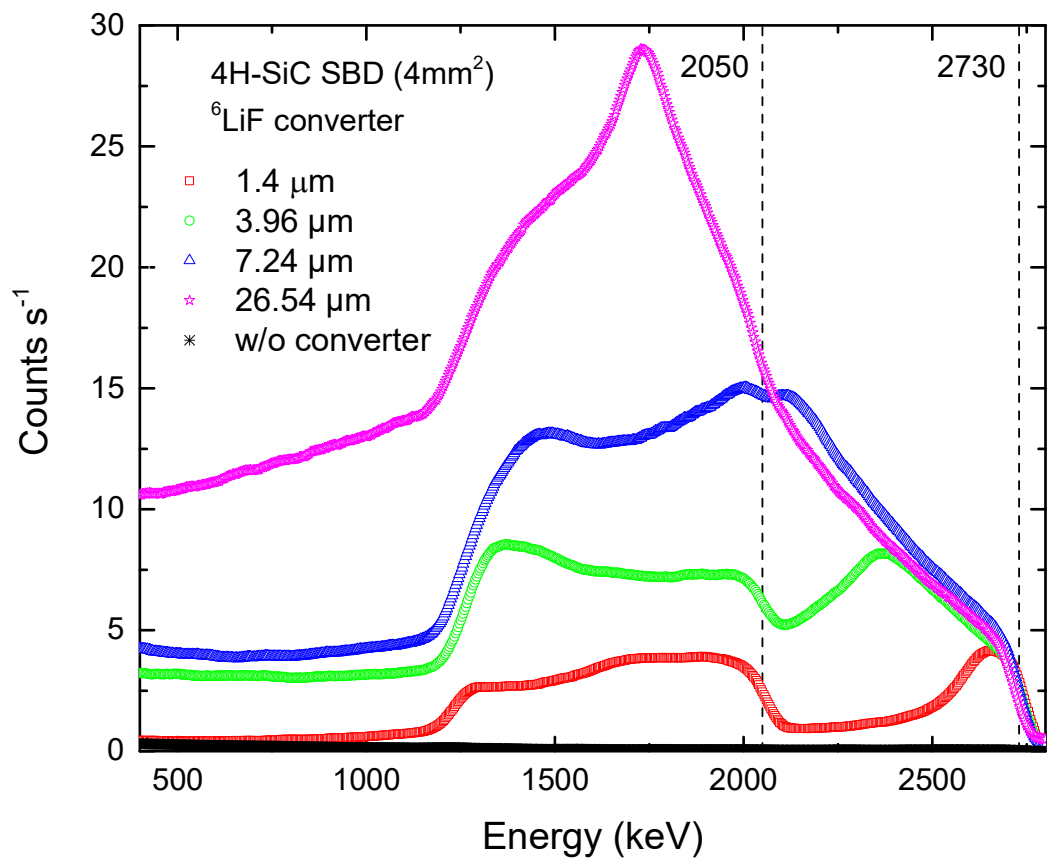

Figure 9. Radiation response of the $4 \mathrm{H}-\mathrm{SiC} \mathrm{SBD}$ equipped with ${ }^{6} \mathrm{LiF}$ thermal neutron converter layers with different thicknesses to the neutron field. Data adapted from Ref. [20].

Fast neutrons could be measured directly or with polyethylene-based converters $[5,10,38]$. The first attempts were made by Flamming et al. [10]. In this study, $2.5 \mathrm{MeV}$ neutron response spectra were measured with and without polyethylene converters. The higher sensitivity was obtained with converters.

Although detection of fast neutrons is possible due to the elastic scattering of fast neutrons with Si or C atoms, the probability of such event and, therefore, the efficiency of the detector, increases as the epitaxial layer thickness increases. High-quality thick 
epitaxial layers $(>250 \mu \mathrm{m})$ used for radiation detection have not yet been reported. This has hindered the successful application of $4 \mathrm{H}-\mathrm{SiC}$ for direct fast neutron detection. It is not unreasonable to expect that further advances will be made with an increase in the thicknesses of high-quality epitaxial layers.

\subsection{Response to X-rays and Gamma Radiation}

While $4 \mathrm{H}-\mathrm{SiC}$ SBDs have proven themselves as efficient radiation detectors for alpha particles and thermal neutrons, radiation response to X-rays is less explored. Puglisi et al. [12] studied $4 \mathrm{H}-\mathrm{SiC}$ for soft $\mathrm{X}$-ray $(<20 \mathrm{keV})$ detection and spectroscopy. They used various $4 \mathrm{H}-\mathrm{SiC}$ epitaxial layer thicknesses and Schottky contact areas and achieved an energy resolution of about 700 and $1300 \mathrm{eV} \mathrm{FWHM} \mathrm{for} 1 \mathrm{~mm}^{2}$ and $10 \mathrm{~mm}^{2}$ detectors measured at RT, respectively. Figure 10 shows the $X$-ray spectrum from a ${ }^{241} \mathrm{Am}$ source using a $\mathrm{SiC}$ detector in the energy range of 0 to $28 \mathrm{keV}$ [12].

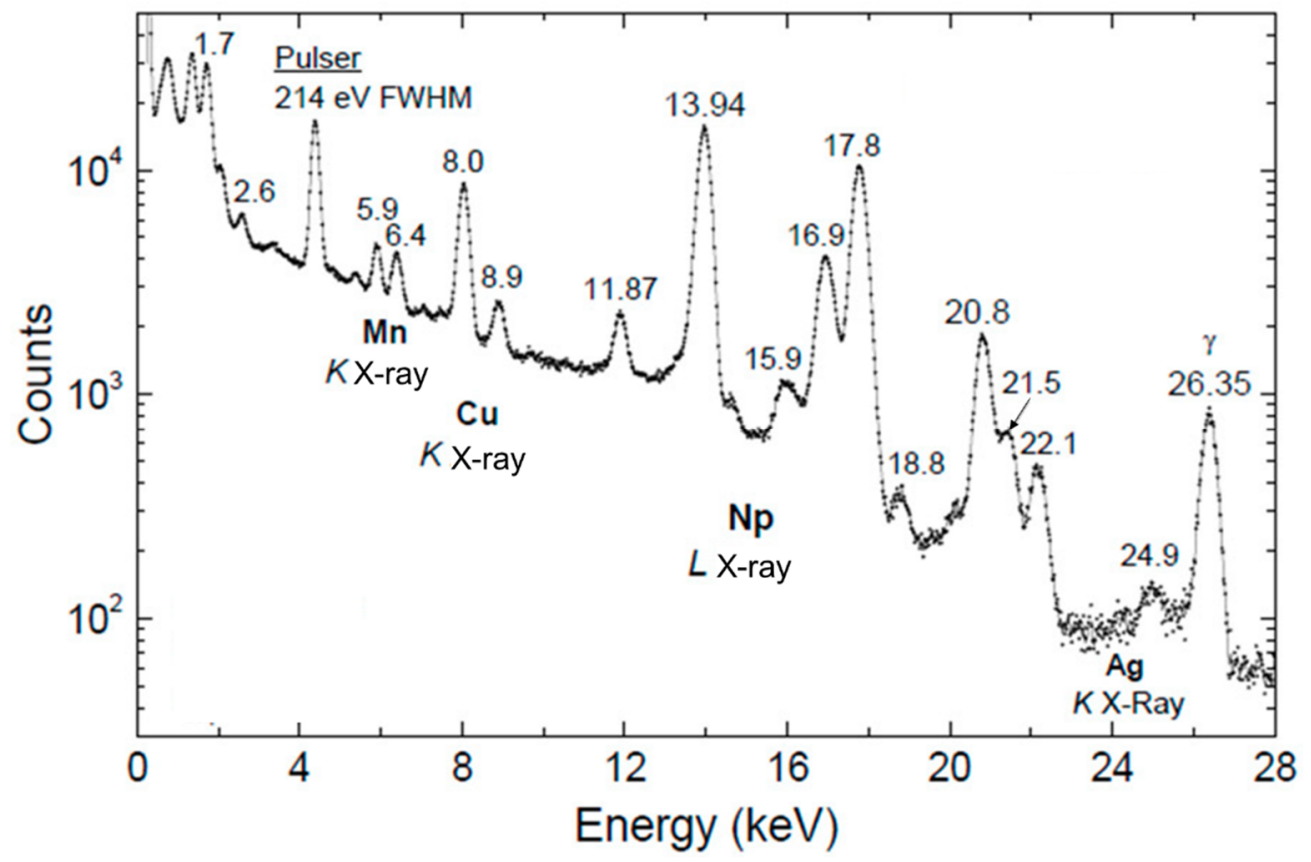

Figure 10. X-ray spectrum from a ${ }^{241} \mathrm{Am}$ source measured at RT using a SiC detector in the energy range 0 to $28 \mathrm{keV}$. Data were taken from Ref. [12].

Significant progress regarding $X$-ray detection was achieved by Lees et al. [11]. They proposed a novel $4 \mathrm{H}-\mathrm{SiC}$ SBD architecture, as shown in Figure 11. The semi-transparent $4 \mathrm{H}-\mathrm{SiC}$ SBD has an ultra-thin Schottky contact $(18 \mathrm{~nm})$, a gold annular overlayer, and a gold corner-contact pad. It was shown that semi-transparent $4 \mathrm{H}-\mathrm{SiC}$ SBDs exhibit higher efficiency for low-energy $(<5 \mathrm{keV})$ X-rays compared to conventional SBD structures (as shown in Figure 1). They achieved an energy resolution of about $1.47 \mathrm{keV}$ FWHM at $22 \mathrm{keV}$ measured at RT [11]. Figure 11 shows a schematic of the semi-transparent diode cross-section and a schematic of the semi-transparent Schottky contact and a gold bond pad.

The radiation response to gamma rays is by far the least explored. Among the first attempts to apply $4 \mathrm{H}-\mathrm{SiC}$ SBDs was in work by Mandal et al. [39]. SBDs used in their study included a $50 \mu \mathrm{m}$-thick $4 \mathrm{H}-\mathrm{SiC}$ epitaxial layer and Schottky contacts with a diameter of $3.2 \mathrm{~mm}$. They reported a $2.1 \%$ energy resolution for $59.6 \mathrm{keV}$ gamma rays. Figure 12 shows the radiation response to gamma radiation of three different $4 \mathrm{H}-\mathrm{SiC}$ SBDs. SBD parameters were a $25 \mu \mathrm{m}$-thick $4 \mathrm{H}$-SiC epitaxial layer and Schottky contact areas of 1,4 , and $9 \mathrm{~mm}^{2}$. It was observed that the sensitivity of the 4H-SiC SBD with the largest Schottky contact area decreased. Such behavior was not observed for the radiation response of the $4 \mathrm{H}-\mathrm{SiC}$ SBDs to alpha particles, for example. 


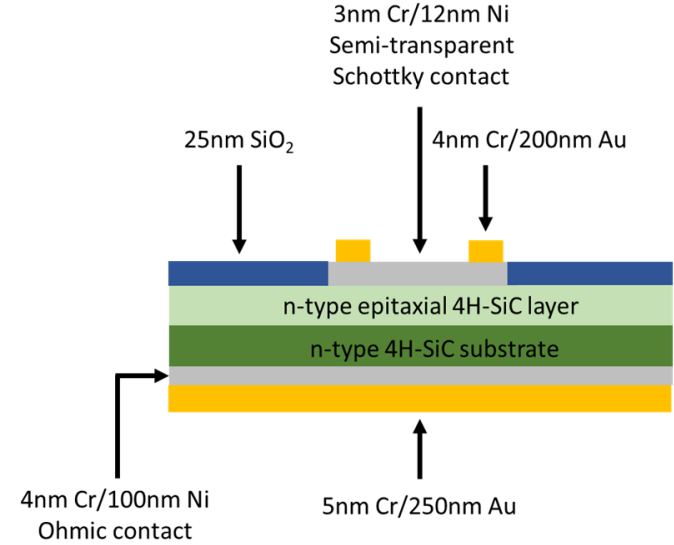

(a)

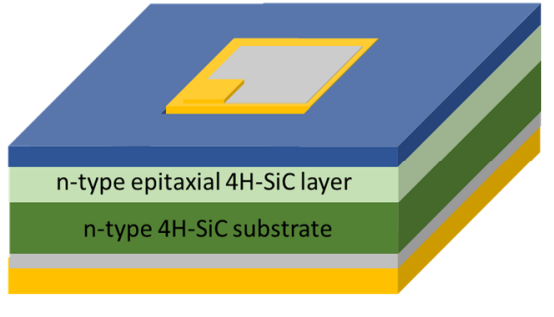

(b)

Figure 11. Semi-transparent Schottky diode. (a) Cross-section of semi-transparent SBD, and (b) semi-transparent Schottky contact and a gold bond pad (top view). Adapted from Ref. [11].

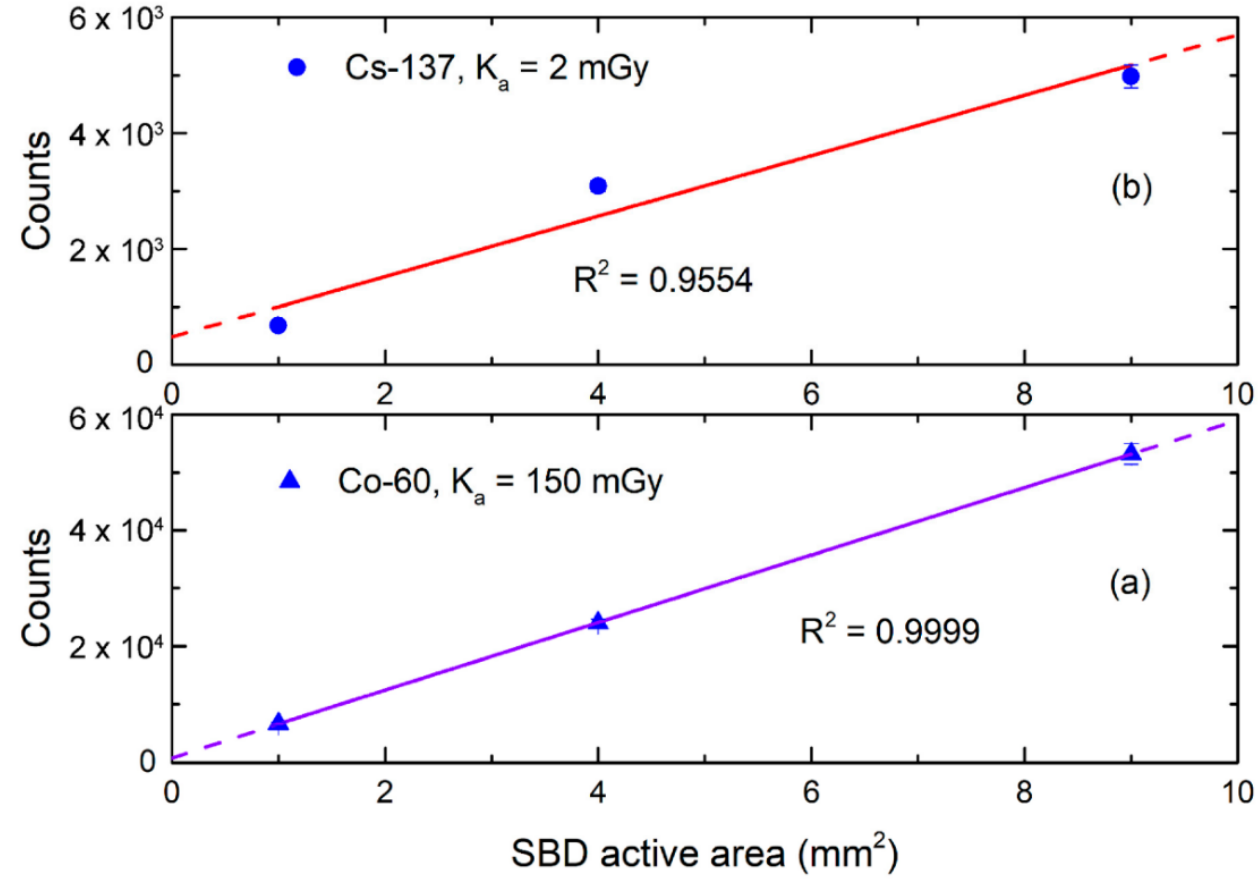

Figure 12. Response of three different $4 \mathrm{H}-\mathrm{SiC}$ SBDs $\left(1 \mathrm{~mm}^{2}, 4 \mathrm{~mm}^{2}\right.$, and $9 \mathrm{~mm}^{2}$ areas) to gamma sources of Cs-137 (a) and Co-60 (b). The solid line shows linear fit for three 4H-SiC SBDs. Data reproduced from Ref. [9].

With recent advances in using Mo as a Schottky contact [40], the Mo/4H-SiC SBDs were investigated as photon-counting detectors for X-ray and gamma-ray spectroscopy [41]. Lioliou et al. [41] used SBDs with a $35 \mu \mathrm{m}$-thick epitaxial layer and achieved an energy resolution of $1.67 \mathrm{keV}$ FWHM at $5.9 \mathrm{keV}$ and $1.6 \mathrm{keV}$ FWHM at $59.54 \mathrm{keV}$, all measured at $\mathrm{RT}$. As seen from different studies on X-ray response measurements, energy resolution can be increased by making additional modifications on the $4 \mathrm{H}-\mathrm{SiC}$ SBDs structure, mainly in Schottky contacts.

\section{Conclusions}

The main idea behind this review is to provide a practical overview of the main stages in applying $4 \mathrm{H}-\mathrm{SiC}$ SBDs for radiation detection. This includes SBDs fabrication, electrical characterization of SBDs, and measuring the radiation response. The best results so far 
have been achieved to detect alpha particles and thermal neutrons. As the thicknesses of the high-quality $4 \mathrm{H}-\mathrm{SiC}$ epitaxial layers are increasing, it is expected that advancement in direct fast neutron detection will be achieved shortly. Moreover, it is not unrealistic to expect additional progress with radiation detection of $\mathrm{X}$-rays in the following years, too.

Funding: The present work was financially supported by the NATO Science for Peace and Security Programme, project no. G5674.

Data Availability Statement: Data are contained within the article.

Acknowledgments: The author would like to thank Ivan Capan, Jasminka Popović, Robert Bernat, and Tihomir Knežević for useful comments on the manuscript.

Conflicts of Interest: The author declares no conflict of interest.

\section{References}

1. Kimoto, T.; Cooper, J.A. Fundamentals of Silicon Carbide Technology: Growth, Characterization, Devices, and Applications; John Wiley \& Sons Singapore Pte. Ltd.: Hoboken, NJ, USA, 2014. [CrossRef]

2. Yang, A.; Murata, K.; Miyazawa, T.; Tawara, T.; Tsuchida, H. Analysis of carrier lifetimes in N + B-doped n-type 4H-SiC epilayers. J. Appl. Phys. 2019, 126, 055103. [CrossRef]

3. Bathen, M.E.; Galeckas, A.; Müting, J.; Ayedh, H.M.; Grossner, U.; Coutinho, J.; Frodason, Y.K.; Vines, L. Electrical charge state identification and control for the silicon vacancy in 4H-SiC. NPJ Quantum Inf. 2019, 5, 111. [CrossRef]

4. Radulović, V.; Yamazaki, Y.; Pastuović, Ž.; Sarbutt, A.; Ambrožič, K.; Bernat, R.; Ereš, Z.; Coutinho, J.; Ohshima, T.; Capan, I.; et al. Silicon carbide neutron detector testing at the JSI TRIGA reactor for enhanced border and port security. Nucl. Instrum. Methods Phys. Res. Sect. A Accel. Spectrometers Detect. Assoc. Equip. 2020, 972, 164122. [CrossRef]

5. Coutinho, J.; Torres, V.J.B.; Capan, I.; Brodar, T.; Ereš, Z.; Bernat, R.; Radulović, V. Silicon carbide diodes for neutron detection. Nucl. Inst. Methods Phys. Res. A 2020, 986, 164793. [CrossRef]

6. Ruddy, F.H.; Seidel, J.G.; Chen, H.; Dulloo, A.R.; Ryu, S.H. High-resolution alpha-particle spectrometry using silicon carbide semiconductor detectors. IEEE Nucl. Sci. Symp. Conf. Rec. 2005, 3, 1231-1235.

7. Zat'ko, B.; Hrubčín, L.; Šagátová, A.; Osvald, J.; Boháček, P.; Kováčová, E.; Halahovets, Y.; Rozov, S.V.; Sandukovskij, V.G. Study of Schottky barrier detectors based on a high quality 4H-SiC epitaxial layer with different thickness. Appl. Surf. Sci. 2021, 536, 147801. [CrossRef]

8. Kleppinger, J.W.; Chaudhuri, S.K.; Karadavut, O.F.; Mandal, K.C. Defect characterization and charge transport measurements in high-resolution $\mathrm{Ni} / \mathrm{n}-4 \mathrm{H}-\mathrm{SiC}$ Schottky barrier radiation detectors fabricated on $250 \mu \mathrm{m}$ epitaxial layers. J. Appl. Phys. 2021, 129, 244501. [CrossRef]

9. Bernat, R.; Capan, I.; Bakrač, L.; Brodar, T.; Makino, T.; Ohshima, T.; Pastuović, Ž.; Sarbutt, A. Response of 4h-sic detectors to ionizing particles. Crystals 2021, 11, 10. [CrossRef]

10. Flammang, R.W.; Seidel, J.G.; Ruddy, F.H. Fast neutron detection with silicon carbide semiconductor radiation detectors. Nucl. Instrum. Methods Phys. Res. Sect. A Accel. Spectrometers Detect. Assoc. Equip. 2007, 579, 177-179. [CrossRef]

11. Lees, J.E.; Bassford, D.J.; Fraser, G.W.; Horsfall, A.B.; Vassilevski, K.V.; Wright, N.G.; Owens, A. Semi-transparent SiC Schottky diodes for X-ray spectroscopy. Nucl. Instrum. Methods Phys. Res. Sect. A Accel. Spectrometers Detect. Assoc. Equip. 2007, 578, 226-234. [CrossRef]

12. Puglisi, D.; Bertuccio, G. Silicon Carbide Microstrip Radiation Detectors. Micromachines 2019, 10, 835. [CrossRef] [PubMed]

13. Gao, R.L.; Du, X.; Ma, W.Y.; Sun, B.; Ruan, J.L.; Ouyang, X.; Li, H.; Chen, L.; Liu, L.Y.; Ouyang, X.P. Radiation tolerance analysis of 4H-SiC PIN diode detectors for neutron irradiation. Sens. Actuators A Phys. 2022, 333, 113241. [CrossRef]

14. Chaudhuri, S.K.; Karadavut, O.; Kleppinger, J.W.; Mandal, K.C. High-resolution radiation detection using Ni/SiO $2 / n-4 \mathrm{H}-\mathrm{SiC}$ vertical metal-oxide-semiconductor capacitor. J. Appl. Phys. 2021, 130, 074501. [CrossRef]

15. Grant, J.; Bates, B.; Cunningham, W.; Blue, A.; Melone, J.; McEwan, F.; Vaitkus, J.; Gaubas, E.; O'Shea, V. GaN as a radiation hard particle detector. Nucl. Instrum. Methods Phys. Res. Sect. A Accel. Spectrometers Detect. Assoc. Equip. 2007, 576, 60-65. [CrossRef]

16. Kania, D.R.; Landstrass, M.I.; Plano, M.A.; Pan, L.S.; Han, S. Diamond radiation detectors. Diam. Relat. Mater. 1993, 2, $1012-1019$. [CrossRef]

17. Chen, J.; Tang, H.; Li, Z.; Zhu, Z.; Gu, M.; Xu, J.; Ouyang, X.; Liu, B. Highly sensitive X-ray detector based on a $\beta$-Ga2O3:Fe single crystal. Opt. Express 2021, 29, 23292-23299. [CrossRef]

18. Capan, I.; Brodar, T.; Coutinho, J.; Ohshima, T.; Markevich, V.P.; Peaker, A.R. Acceptor levels of the carbon vacancy in $\$ 4 \mathrm{H} \$-S i C$ : Combining Laplace deep level transient spectroscopy with density functional modeling. J. Appl. Phys. 2018, 124, 245701. [CrossRef]

19. Pastuović, Z.; Siegele, R.; Capan, I.; Brodar, I.; Sato, S.; Ohshima, T. Deep level defects in 4H-SiC introduced by ion implantation: The role of single ion regime. J. Phys. Condens. Matter 2017, 29, 475701. [CrossRef]

20. Bernat, R.; Bakrač, L.; Radulović, V.; Snoj, L.; Makino, T.; Ohshima, T.; Pastuović, Ž.; Capan, I. 4H-SiC Schottky Barrier Diodes for Efficient Thermal Neutron Detection. Materials 2021, 14, 5105. [CrossRef] 
21. Brodar, T.; Capan, I.; Radulović, V.; Snoj, L.; Pastuović, Z.; Coutinho, J.; Ohshima, T. Laplace DLTS study of deep defects created in neutron-irradiated n-type 4H-SiC. Nucl. Instrum. Methods Phys. Res. Sect. B Beam Interact. Mater. Atoms. 2018, 437, 27-31. [CrossRef]

22. Capan, I.; Brodar, T.; Makino, T.; Radulovic, V.; Snoj, L. M-Center in Neutron-Irradiated 4H-SiC. Crystals 2021, 11, 1404. [CrossRef]

23. Battistoni, G.; Cerutti, F.; Fassò, A.; Ferrari, A.; Muraro, S.; Ranft, J.; Roesler, S.; Sala, P.R. The FLUKA code: Description and benchmarking. AIP Conf. Proc. 2007, 896, 31-49.

24. Peaker, A.R.; Markevich, V.P.; Coutinho, J. Tutorial: Junction spectroscopy techniques and deep-level defects in semiconductors. J. Appl. Phys. 2018, 123, 161559. [CrossRef]

25. Son, N.T.; Trinh, X.T.; Løvlie, L.S.; Svensson, B.G.; Kawahara, K.; Suda, J.; Kimoto, T.; Umeda, T.; Isoya, J.; Makino, T.; et al. Negative-U System of Carbon Vacancy in 4H-SiC. Phys. Rev. Lett. 2012, 109, 187603. [CrossRef]

26. Capan, I.; Brodar, T.; Pastuović, Z.; Siegele, R.; Ohshima, T.; Sato, S.I.; Makino, T.; Snoj, L.; Radulović, V.; Coutinho, J.; et al. Double negatively charged carbon vacancy at the h- and k-sites in 4H-SiC: Combined Laplace-DLTS and DFT study. J. Appl. Phys. 2018, 123, 161597. [CrossRef]

27. Alfieri, G.; Mihaila, A. Isothermal annealing study of the EH1 and EH3 levels in n-type 4H-SiC. J. Phys. Condens. Matter 2020, 32, 46. [CrossRef]

28. Karsthof, R.; Bathen, M.E.; Galeckas, A.; Vines, L. Conversion pathways of primary defects by annealing in proton-irradiated n-type 4H-SiC. Phys. Rev. B 2020, 102, 184111. [CrossRef]

29. Brodar, T.; Bakrač, L.; Capan, I.; Ohshima, T.; Snoj, L.; Radulović, V.; Pastuović, Ž. Depth Profile Analysis of Deep Level Defects in 4H-SiC Introduced by Radiation. Crystals 2020, 10, 845. [CrossRef]

30. Mandal, K.C.; Chaudhuri, S.K.; Nguyen, K. An overview of application of 4H-SiC n-type epitaxial Schottky barrier detector for high resolution nuclear detection. In Proceedings of the IEEE Nuclear Science Symposium and Medical Imaging Conference, Seoul, Korea, 27 October-2 November 2013; pp. 1-6. [CrossRef]

31. Kleppinger, J.W.; Chaudhuri, S.K.; Karadavut, O.F.; Mandal, K.C. Role of deep levels and barrier height lowering in current-flow mechanism in $150 \mu \mathrm{m}$ thick epitaxial n-type 4H-SiC Schottky barrier radiation detectors. Appl. Phys. Lett. 2021, 119, 063502. [CrossRef]

32. Zat'ko, B.; Dubecký, F.; Šagátová, A.; Sedlačová, K.; Ryć, L. High resolution alpha particle detectors based on $4 \mathrm{H}-\mathrm{SiC}$ epitaxial layer. J. Instrum. 2015, 10, C04009. [CrossRef]

33. Chaudhuri, S.K.; Zavalla, K.J.; Mandal, K.C. High resolution alpha particle detection using 4H-SiC epitaxial layers: Fabrication, characterization, and noise analysis. Nucl. Instrum. Meth. Phys. Res. A 2013, 728, 97. [CrossRef]

34. McGregor, D.S.; Hammig, M.D.; Yang, Y.H.; Gersch, H.K.; Klann, R.T. Design considerations for thin film coated semiconductor thermal neutron detectors-I: Basics regarding alpha particle emitting neutron reactive films. Nucl. Instrum. Methods Phys. Res. Sect. A Accel. Spectrometers Detect. Assoc. Equip. 2003, 500, 272-308. [CrossRef]

35. Giudice, A.L.; Fasolo, F.; Durisi, E.; Manfredotti, C.; Vittone, E.; Fizzotti, F.; Zanini, A.; Rosi, G. Performances of 4H-SiC Schottky diodes as neutron detectors. Nucl. Instrum. Methods Phys. Res. Sect. A Accel. Spectrometers Detect. Assoc. Equip. 2007, 583, 177-180. [CrossRef]

36. Sedlačková, K.; Zat’ko, B.; Šagátová, A.; Nečas, V.; Boháček, P.; Sekáčová, M. Comparison of semi-insulating GaAs and 4HSiC-based semiconductor detectors covered by LiF film for thermal neutron detection. Appl. Surf. Sci. 2018, 461, 242-248. [CrossRef]

37. Uher, J.; Holý, T.; Jakůbek, J.; Lehmann, E.; Pospíšil, S.; Vacík, J. Performance of a pixel detector suited for slow neutrons. Nucl. Instrum. Methods Phys. Res. Sect. A Accel. Spectrometers Detect. Assoc. Equip. 2005, 542, 283-287. [CrossRef]

38. Ruddy, F.H.; Dulloo, A.R.; Seidel, J.G.; Das, M.K.; Ryu, S.H.; Agarwa, A.K. The fast neutron response of $4 \mathrm{H}$ silicon carbide semiconductor radiation detectors. IEEE Trans. Nucl. Sci. 2006, 53, 1666-1670. [CrossRef]

39. Mandal, K.C.; Muzykov, P.G.; Chadhuri, S.K.; Terry, J.R. Low Energy X-Ray and $\gamma$-Ray Detectors Fabricated on n-type 4H-SiC Epitaxial Layer. IEEE Trans. Nucl. Sci. 2013, 60, 2888-2893. [CrossRef]

40. Chen, K.; Cao, F.; Yang, Z.; Li, x.; Yang, J.; Shi, D.; Wang, Y. Improved interface characteristics of Mo/4H-SiC schottky contact. Solid-State Electron. 2021, 185, 108152. [CrossRef]

41. Lioliou, G.; Renz, A.B.; Shah, V.A.; Gammon, P.M.; Barnett, A.M. Mo/4H-SiC Schottky diodes for room temperature X-ray and $\gamma$-ray spectroscopy. Nucl. Instrum. Methods Phys. Res. Sect. A Accel. Spectrometers Detect. Assoc. Equip. 2022, $1027,166330$. [CrossRef] 